Research Article

\title{
Personnel Casualty Assessment for Explosion in the Subway Platform
}

\author{
Jinju Zhang ${ }^{1,2}$ and Liqiong Wang $\mathbb{D}^{1}$ \\ ${ }^{1}$ State Key Laboratory of Explosion Science and Technology, Beijing Institute of Technology, Beijing 100081, China \\ ${ }^{2}$ School of Public Security, People's Public Security University of China, Beijing 100038, China \\ Correspondence should be addressed to Liqiong Wang; wlq2018@sina.com
}

Received 20 October 2018; Revised 3 January 2019; Accepted 20 May 2019; Published 10 June 2019

Academic Editor: Isabelle Sochet

Copyright (c) 2019 Jinju Zhang and Liqiong Wang. This is an open access article distributed under the Creative Commons Attribution License, which permits unrestricted use, distribution, and reproduction in any medium, provided the original work is properly cited.

\begin{abstract}
The subway station is easy to be attacked by terrorist bombings, and it will cause heavy casualties. In this paper, a comprehensive casualty assessment method for personnel in the subway structure was established based on the existing personnel injury model. The spatial distribution characteristics of the shock wave suffered by the personnel in the subway platform were obtained. Combined with the comprehensive casualty assessment method, the personnel casualty area for the explosions in the subway platform was divided. The results show that for the same explosive charge, the maximum positive phase impulse generated by the explosion at the edge of the platform is smallest. The "notch effect" for the stair exit will increase the shock wave load. When the explosive is exploded in the center of the platform, the smaller the explosive charge is, the more obvious the "notch effect" is. When the explosive charge reaches $40 \mathrm{~kg}$, the personnel safety area is reduced to a certain extent behind the stair except for the explosion happening at the stair. Also, the higher the shield door is, the larger the safety area behind the stair is.
\end{abstract}

\section{Introduction}

In recent years, the subway as a crowded public space has gradually become the preferred target for terrorist attacks. Because of the closed underground structure adopted in the subway system, the propagation law of the shock wave generated by the explosion in the subway structure is much more complicated than that in the free atmospheric space. Hence, the casualties caused by explosion are completely different from those in the unconstraint space. So far, many efforts have been devoted to the propagation law of explosive shock waves in the structure and the dynamic response of the structure for the explosion in the underground structures such as subway. Rigas and Sklavounos [1] calculated the propagation process of shock wave for the explosion in complex constrained space structures with CFX. The Italian European Structural Assessment Laboratory (ELSA) [2] used the finite element software to simulate the propagation of shock waves and the damage of carriage structure for the explosion in subway trains; $\mathrm{Wu}$ et al. [3] proposed a test procedure for the phenomenon of large-scale underground explosion and studied the propagation characteristics of stress wave in soil medium. Li et al. [4] compiled an analytical procedure for the dynamic response of double-track subway tunnel under unilateral tunnel explosion load by using FORTRAN program. Choi et al. [5] obtained the change of the effective strain of the concrete lining structure of the tunnel with the parameters such as explosive charge, explosion distance, and tunnel diameter by numerical simulation of the explosion.

In fact, the explosive charge used in the terrorist incidents in the subway is only few kilograms of TNT equivalent. The station structure cannot be completely damaged in this case but can cause the casualties. So, it is a key issue to reasonably assess the impact of personnel injury caused by explosions in the subway structure. Experimental and theoretical research has been conducted on the evaluation criteria of personnel injury by the effect of explosion. 
For example, "TM5-1300 Antiaccidental Explosive Design Manual" of the United States [6] proposed injury standard of shock wave with duration of $3 \sim 5 \mathrm{~ms}$ to the human body. $\mathrm{Li}$ [7] gave the overpressure threshold corresponding to different casualty levels through a large number of animal tests combined with the relevant standards of the United States and the Soviet Union. Li et al. [8] analyzed the casualties of rabbits at different distances from the explosion point through the free-field explosion test and obtained the safety threshold of the shock wave for rabbits and the safety distance for different charges. Furthermore, Pietersen [9] obtained the harm equivalent and the formula of injury probability caused by the overpressure. Ferradás et al. [10] obtained the method of directly analyzing the impact of the shock wave to personnel injury on the existing characteristic curve of shock wave overpressure-impulse-distance.

Compared with many shock wave injury criteria, it is found that there are some differences in shock wave injury criteria proposed due to different test conditions. In this paper, the personnel injury model suitable for the explosion inside the subway structure is applied to conduct the indepth study.

\section{Method for Assessing Personnel Injury by Blast Loading in Subway}

The severity of shock wave injury to personnel is usually measured by overpressure and positive phase impulse. The shock wave generated by the explosion in the subway structure is a complex shock wave [11], which can produce multiple reflection peaks. The maximum peak overpressure and positive phase impulse in the simulation are evaluated as

$$
\Delta P_{\mathrm{m}}=\max \left(p(t)-p_{0}\right), \quad \forall t \in\left[0, t_{\text {sim }}\right],
$$

where $\Delta P_{\mathrm{m}}$ is the maximum peak overpressure, $\mathrm{Pa} ; p_{0}$ is the standard atmospheric pressure, $\mathrm{Pa}$; and $t_{\text {sim }}$ is the entire simulated time, $s$.

$$
i=\int_{0}^{t^{+}}\left(p(t)-p_{0}\right) d t, \quad \forall t^{+} \in\left[0, t_{\text {sim }}\right],
$$

where $i$ is the positive phase impulse of shock wave, Pa.s, and $t^{+}$is the action time of positive pressure of shock wave, s.

The probit model is commonly used for the casualty assessment. There is a certain logarithmic relationship between probit units and reaction injury factors $[10,12]$, and the general formula is as follows:

$$
Y=A+B \ln x
$$

where $Y$ is the probit units, $x$ is the injury variable of a certain injury event, and $A$ and $B$ are the parameters of the probit unit model.

Each individual injury caused by explosion can be evaluated by a corresponding probit unit model. The lung injury model is based on overpressure and impulse given by Bowen et al. [13], but this model, developed from free-field blasts, is not applicable to explosions in the subway. Therefore, in this paper, the adjusted severity of injury index (ASII) scoring method, applicable to complex shock wave, is used for lung injury assessment $[14,15]$, and the mathematical model is as follows:

$$
\frac{V_{\mathrm{AX}}}{\Delta P_{\mathrm{m}}}= \begin{cases}-4.1863 t_{\mathrm{eq}}^{2}+2.003 \times 10^{-2} t_{\mathrm{eq}}+7.982 \times 10^{-9}, & \text { if } t_{\mathrm{eq}} \leq 0.001 \mathrm{~s}, \\ f_{1}\left(\Delta P_{\mathrm{m}}, i\right) f_{2}\left(\Delta P_{\mathrm{m}}\right)+1.589 \times 10^{-5}, & \text { otherwise, }\end{cases}
$$

where $V_{\mathrm{AX}}$ is the maximum inward chest wall velocity, $\mathrm{m} / \mathrm{s}$, and $t_{\mathrm{eq}}$ is the equivalent triangular pulse duration, $\mathrm{s}$, and calculated as

$$
\begin{aligned}
t_{\mathrm{eq}}= & \frac{2 i}{\Delta P_{\mathrm{m}}}, \\
f_{1}\left(\Delta P_{\mathrm{m}}, i\right)= & \frac{4.5 \times 10^{-5}}{1+\exp \left[\left(-6.806-\ln \left(t_{\mathrm{eq}}\right)\right) / 0.845\right]} \\
& -2.1147 \times 10^{-5}, \\
f_{2}\left(\Delta P_{\mathrm{m}}\right)= & -7.3786 \times 10^{-19} \Delta P_{\mathrm{m}}^{3}+1.8576 \times 10^{-12} \Delta P_{\mathrm{m}}^{2} \\
& -2.0727 \times 10^{-6} \Delta P_{\mathrm{m}}+1.579, \\
\text { ASII }= & \left(0.124+0.117 V_{\mathrm{AX}}\right)^{2.63} .
\end{aligned}
$$

The relationship between injury degree and ASII score is shown in Table 1 [14].
The assessment model of the eardrum injury caused by the direct action of shock waves is shown in the following equation [11]:

$$
Y_{2}=-12.6+1.524 \ln \Delta P_{\mathrm{m}}
$$

The throwing injury caused by the indirect action of the shock wave can be divided into the whole body impact injury and the head impact injury. The injury assessment models are as shown in equations (7) (8) [16].

The whole body impact injury probability model is as follows:

$$
Y_{3}=5-2.44 \ln \left(\frac{7.38 \times 10^{3}}{\Delta P_{\mathrm{m}}}+\frac{1.3 \times 10^{9}}{\Delta P_{\mathrm{m}} \cdot i}\right)
$$

The head impact injury probability model is as follows:

$$
Y_{4}=5-8.49 \ln \left(\frac{2.43 \times 10^{3}}{\Delta P_{\mathrm{m}}}+\frac{4 \times 10^{8}}{\Delta P_{\mathrm{m}} \cdot i}\right) \text {. }
$$

The probability of occurrence can be obtained from the probit unit and can calculated as [17] 
TABLE 1: ASII score corresponding to different injury levels.

\begin{tabular}{lc}
\hline Degree of injury & ASII \\
\hline No injury & $0.0-0.2$ \\
Slight injury to minor injury & $0.2-1.0$ \\
Moderate injuries to serious injuries & $1.0-3.6$ \\
$>50 \%$ lethality rate & $>3.6$ \\
\hline
\end{tabular}

$$
P_{i}=\frac{1}{\sqrt{2 \pi}} \int_{-\infty}^{Y_{i}-5} e^{\left(-u^{2} / 2\right)} d u,
$$

where $P$ is the probability of occurrence; when $Y$ is taken as 5 , the probability of occurrence is $50 \%$.

In this paper, the injury consequences of human body are divided into three types: death, serious injury, and light injury [18]. Combined with the results of individual injury assessment, the comprehensive personnel casualty assessment process for the explosion in the subway structure is obtained, as shown in Figure 1.

\section{Finite Element Model of Explosion in Subway Station}

3.1. Size of the Subway Platform. A typical station in Beijing was chosen as the research object, and it is an island-style and double-column structure. The effective length and the width of the platform are $120 \mathrm{~m}$ and $13 \mathrm{~m}$, respectively. The height at the track and platform is $6 \mathrm{~m}$ and $4.8 \mathrm{~m}$, respectively. The radius of platform column is $0.5 \mathrm{~m}$. Longitudinal distance and horizontal distance between the columns are $6 \mathrm{~m}$ and $7 \mathrm{~m}$, respectively. There is a staircase on the platform from $30 \mathrm{~m}$ to the center of the platform, respectively. Also, the width of each stair is $5 \mathrm{~m}$, with the longitudinal bottom $13 \mathrm{~m}$ long and the short side $4 \mathrm{~m}$ long. There is an exit with $8 \mathrm{~m}$ long and $5 \mathrm{~m}$ wide at the top of the stair. The cross section of the subway platform is shown in Figure 2, and the half of longitudinal section of the subway platform is shown in Figure 3.

3.2. Structure of the Shield Door. At present, there are three main types of shield doors installed in the subway: fullheight and fully closed shield doors, full-height and semiclosed shield doors, and half-height shield doors. The total height of the full-height and fully closed shield door is $3.2 \mathrm{~m}$, whose shield door glass is $2 \mathrm{~m}$ high and the upper cover is $1.2 \mathrm{~m}$ high. The full-height and semiclosed shield door is $2.5 \mathrm{~m}$ high, whose shield door glass is $2 \mathrm{~m}$ high and the upper cover is $0.5 \mathrm{~m}$ high. The height of the semihigh shield door is $1.5 \mathrm{~m}$, whose lower skirting board is $0.5 \mathrm{~m}$ high and the shielding door glass is $1 \mathrm{~m}$ high. The dimensions of the three doors in the longitudinal direction of $20 \mathrm{~m}$ (corresponding to one compartment) are shown in Figures 4-6, respectively.

3.3. Parameters of Explosion Source. Considering human bombs or luggage bombs as the two main sources for terrorist attack, the explosion height of all the explosion sources is determined as $1 \mathrm{~m}$ in this paper. According to the data of the explosive equivalent of various terrorist attacks given in
No. 452 document issued by US Federal Emergency Management Agency [19], the maximum amount of belt and vest type human bomb is about $5 \mathrm{~kg}$ and $10 \mathrm{~kg}$, respectively, and the average amount and maximum amount of ordinary bag type bombs are about $20 \mathrm{~kg}$ and $40 \mathrm{~kg}$, respectively. Therefore, the four TNT equivalents $(5 \mathrm{~kg}, 10 \mathrm{~kg}, 20 \mathrm{~kg}$, and $40 \mathrm{~kg}$ ) are selected in this paper.

Considering the actual cases of the explosion in the subway station and the simulation calculation effect, the center point of the platform is selected as location of the explosion source. And because the personnel at the edge of the platform and at the entrance to the bottom of the stairs are dense, these two positions are also selected. The specific locations of the explosion source are shown in Figure 7.

3.4. Calculation Conditions. Combined with the parameters of the explosion source in the subway platform and the characteristics of the subway platform structure, the calculation conditions of the explosion in the subway platform are shown in Table 2.

3.5. Numerical Model. The AUTODYN software is used to establish model for numerical simulation analysis. Also, in order to improve computational efficiency, the segmentation meshing is used, that is, within $0 \mathrm{~m}-7 \mathrm{~m}, 50 \mathrm{~mm}$ grid is used; for more than $7 \mathrm{~m}, 100 \mathrm{~mm}$ grid is used. With the consideration of the symmetry, $1 / 4$ of the platform is selected to conduct modeling at the center of platform, and 1/2 of the platform is selected for explosion at the edge of the platform and the entrance to the bottom of the stair.

The platform board, wall, and column can be simplified as rigid materials. The boundary of the structure is set as the reflection boundary, and the transmission boundary is set at the exit of stair and the entrance of tunnel. The calculating result of shock wave propagation for the TNT exploding in one-dimension within 1 meter is remapped into the threedimensional model by using REMAP technique. The numerical model is shown in Figure 8.

The arrangement of the monitoring points on the platform plane is as shown in Figure 9 (taking the 1/4 of the platform as an example). The monitoring points are set at intervals of $1 \mathrm{~m}$. The vertical and horizontal intersections in the figure are the monitoring points on the platform plane, and the heights of the monitoring points are $1 \mathrm{~m}$ above the platform. At the stair, the monitoring points are set along the stairs slope where the person stands, and the heights of the monitoring points are $1.53 \mathrm{~m}, 2.07 \mathrm{~m}, 2.60 \mathrm{~m}, 3.13 \mathrm{~m}, 3.67 \mathrm{~m}$, $4.20 \mathrm{~m}, 4.73 \mathrm{~m}, 4.75 \mathrm{~m}$, and $4.79 \mathrm{~m}$ from $31 \mathrm{~m}$ to $39 \mathrm{~m}$.

\section{Analysis of Calculation Results}

4.1. Shock Wave Load Distribution for Explosion of Subway Stations. According to equations (1) and (2), the values of overpressure and positive phase impulse can be obtained by extracting the pressure value at the position of the monitoring point for each numerical simulation, as shown in Figure 10. 


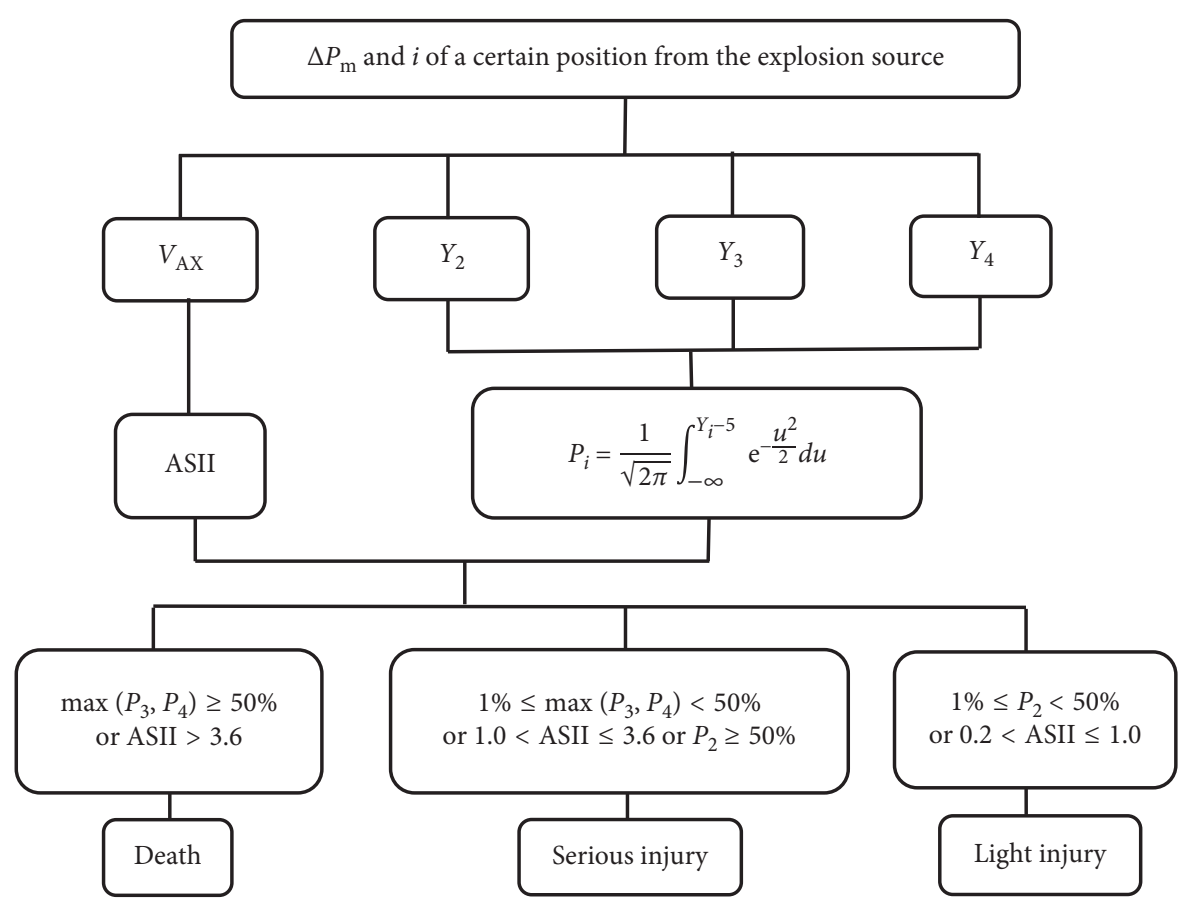

FIGURE 1: Flowchart of comprehensive personnel casualty assessment based on ASII.

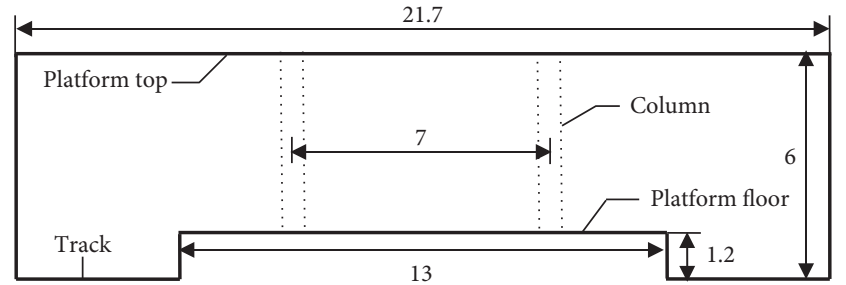

FIGURE 2: Cross-sectional dimension of subway platform (unit: m).

The overpressure peak and positive phase impulse increase with the increase of TNT equivalent. The strength of the shock wave for the explosion on the platform under the different conditions is compared in Table 3.

When TNT equivalent is $40 \mathrm{~kg}$, the maximum overpressure peak is the same because the overpressure at the blasting center is not affected by the surrounding environment. The shock wave continues to spread outwards, and the maximum positive phase impulses under different conditions vary due to the influence of the subway structure. When $40 \mathrm{~kg}$ TNT explodes at the stair entrance, the maximum positive phase impulse is the largest due to the "notch effect" of the stair exit, while the maximum positive phase impulse of the same equivalent exploding at the center of the platform under the other four working conditions (with shield door and unshield door) is relatively close, indicating that the shock waves are mainly reflected by the structural wall of the platform, and the shock wave positive phase duration is similar. The maximum positive phase impulse of the explosion at the edge of the platform is the smallest. That is because the shock wave expands to the train track of platform at the initial stage of propagation, and the shock wave energy is weakened by the effect of pressure relief of the train track.
When the explosive of different TNT equivalent explodes at the center of the platform without the shield door, the shock wave load on the stair slope is enhanced compared with that at other positions of the same section due to the "notch effect" of the stair. Also, the smaller the explosive charge is, the more obvious the "gap effect" is. Since the direction of the shock wave is perpendicular to the normal direction of the stair, the shock wave of large energy will continue to propagate forward due to inertia. The larger the explosive charge is, the greater the inertia is, and the less the pressure relief effect of the stair is. When explosive explodes at the center of the platform with the shield door, the shock wave overpressure and impulse increase near the shield door at the initial stage of explosion due to the reflection of the shield door.

The shock wave overpressure and impulse at the column and the stair will oscillate back and forth due to reflection and diffraction. When the shock wave propagates to the end wall of the platform, the shock wave overpressure and impulse near the end wall of the platform increase due to the reflection effect. The minimum values of the shock wave overpressure and impulse under different working conditions are all located at a certain position behind the stair due to the blocking effect of the stair on the shock wave.

\subsection{Assessment for Personnel Casualty Area on the Platform.} Using the comprehensive assessment method of personnel casualty obtained above, the casualties on the platform are divided into different levels, and different casualties are represented by different colors. Distribution maps of casualties under different conditions are obtained, as shown in Figure 11. 


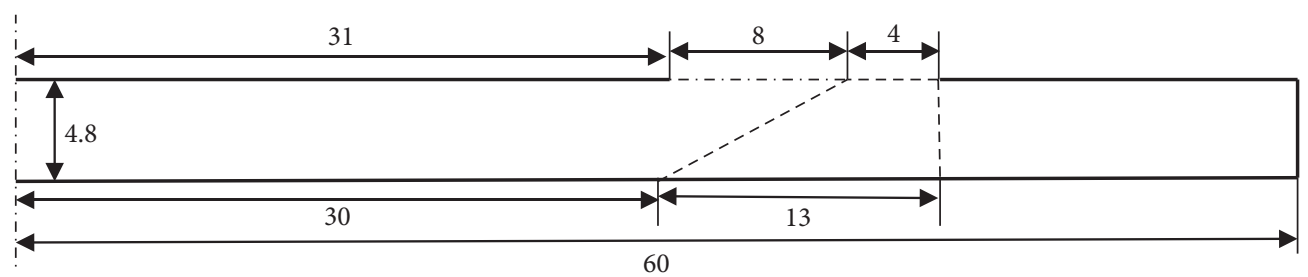

Figure 3: Half of the longitudinal sectional dimension of the subway platform (unit: m).

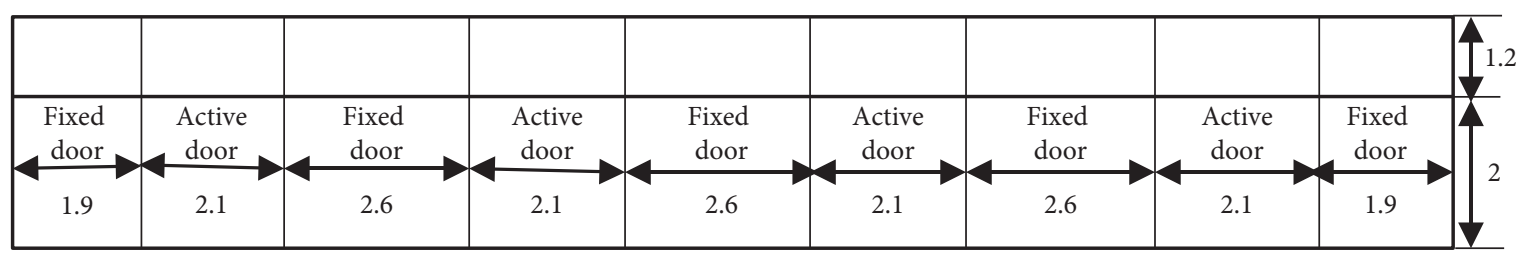

FIGURE 4: Size of full-height and fully closed shield door (unit: $\mathrm{m}$ ).

\begin{tabular}{|c|c|c|c|c|c|c|c|c|}
\hline $\begin{array}{r}\text { Fixed } \\
\text { door }\end{array}$ & $\begin{array}{c}\text { Active } \\
\text { door }\end{array}$ & $\begin{array}{r}\text { Fixed } \\
\text { door }\end{array}$ & $\begin{array}{c}\text { Active } \\
\text { door }\end{array}$ & $\begin{array}{r}\text { Fixed } \\
\text { door }\end{array}$ & $\begin{array}{c}\text { Active } \\
\text { door }\end{array}$ & $\begin{array}{r}\text { Fixed } \\
\text { door }\end{array}$ & $\begin{array}{c}\text { Active } \\
\text { door }\end{array}$ & $\begin{array}{r}\text { Fixed } \\
\text { door }\end{array}$ \\
\hline 1.9 & 2.1 & 2.6 & 2.1 & 2.6 & 2.1 & 2.6 & 2.1 & 1.9 \\
\hline
\end{tabular}

Figure 5: Size of full-height and semiclosed shield door (unit: $\mathrm{m}$ ).

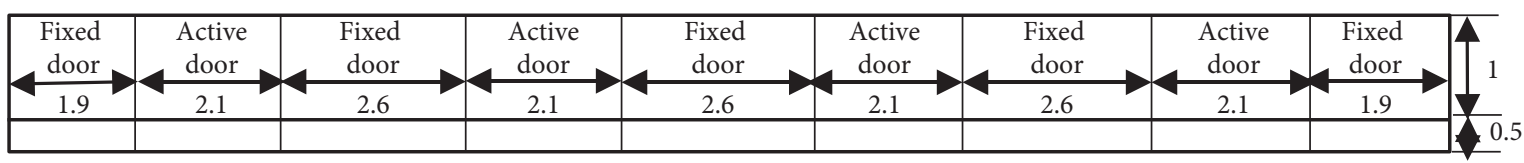

FIgURE 6: Size of semihigh shield door (unit: m).

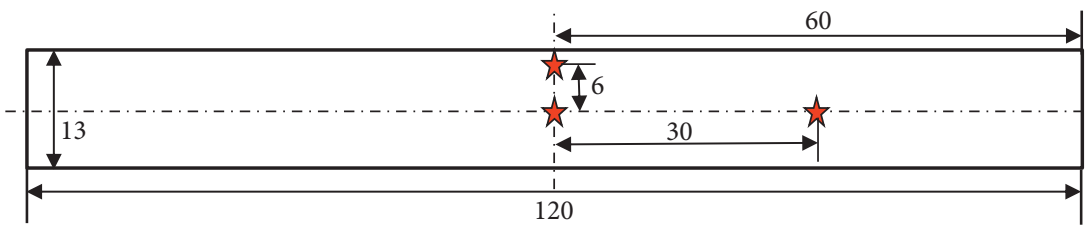

FIgURE 7: The location of the explosion source on the platform (unit: $\mathrm{m}$ ).

TABLe 2: Calculation conditions of explosions in subway platform.

\begin{tabular}{|c|c|c|c|c|c|}
\hline No. & Subn & ray platform structure & Location of explosion source & Equivalent $(\mathrm{kg})$ & Height of explosion source $(\mathrm{m})$ \\
\hline 1 & & \multirow{4}{*}{ No shield door } & \multirow{4}{*}{ Center of the platform } & 5 & \multirow{9}{*}{1} \\
\hline 2 & & & & 10 & \\
\hline 3 & & & & 20 & \\
\hline 4 & & & & 40 & \\
\hline 5 & & No shield door & Edge of the platform & 40 & \\
\hline 6 & & No shield door & Entrance to the bottom of the stair & 40 & \\
\hline 7 & & Full-height and fully closed & & & \\
\hline 8 & Shield door & Full-height and semiclosed & Center of the platform & 40 & \\
\hline 9 & & Half-height & & & \\
\hline
\end{tabular}

The distribution of casualties is irregular due to the influence of the column, stair, and shield door on the platform, but it presents radial expansion with the explosion source.
As the explosive charge increases, the safety area on the platform gradually decreases. When the explosive charge reaches $40 \mathrm{~kg}$, in addition to the explosion that occurs at the stair, the safety area under other conditions is reduced to a 


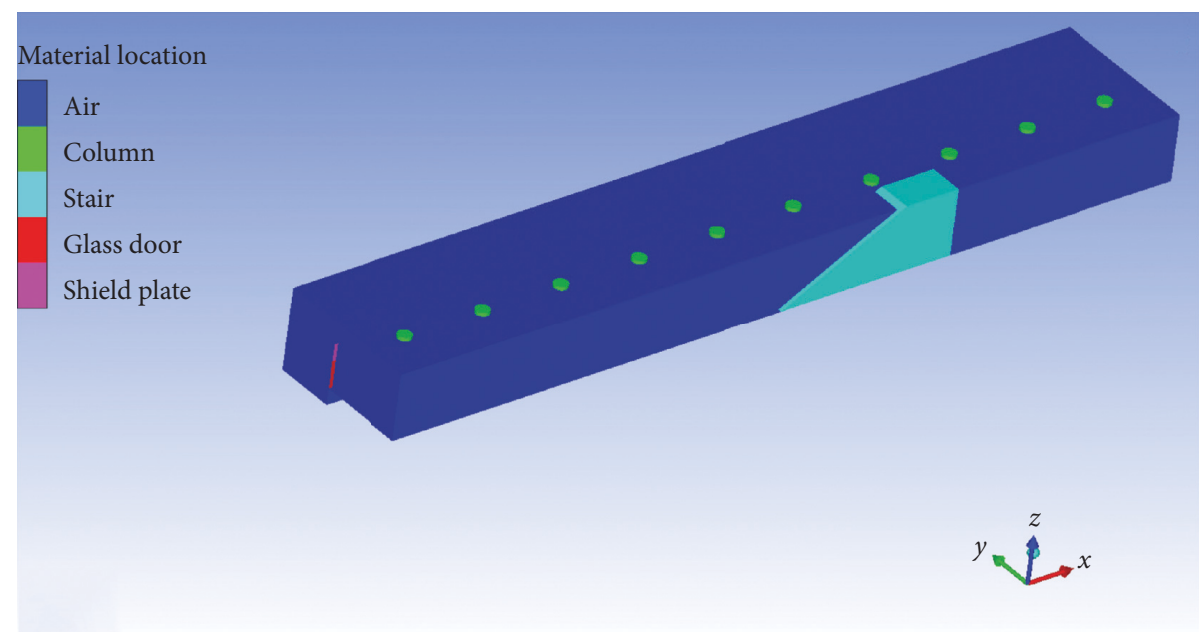

Figure 8: Numerical model of the platform with full-height and fully closed shield doors.

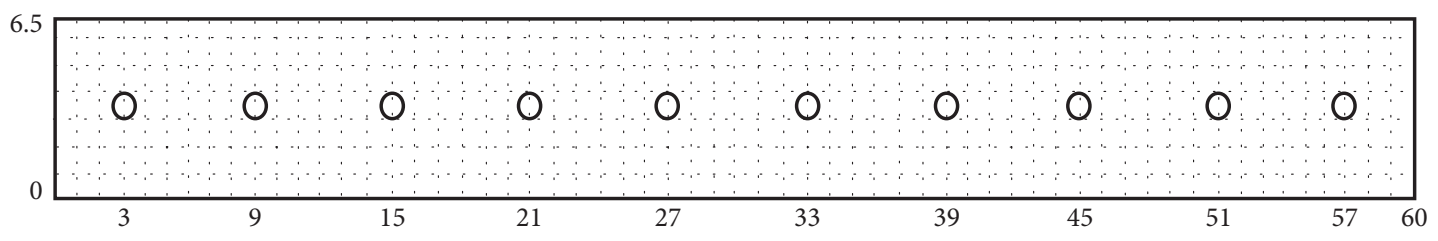

FIgURE 9: Arrangement of monitoring points on the platform plane.
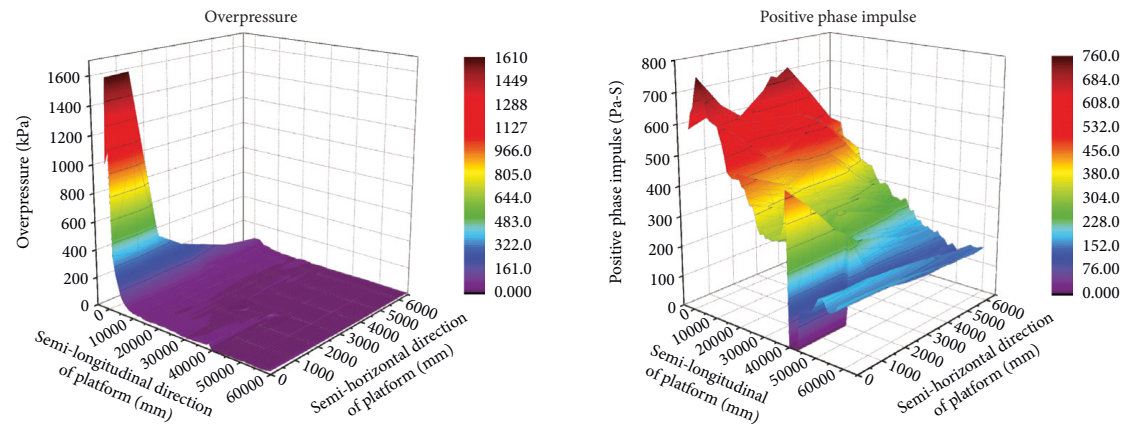

(a)
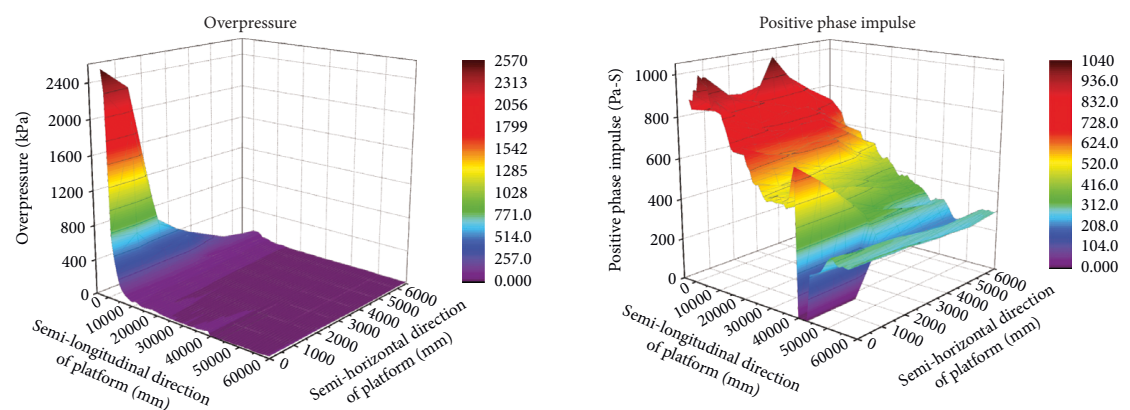

(b)

FIgURE 10: Continued. 

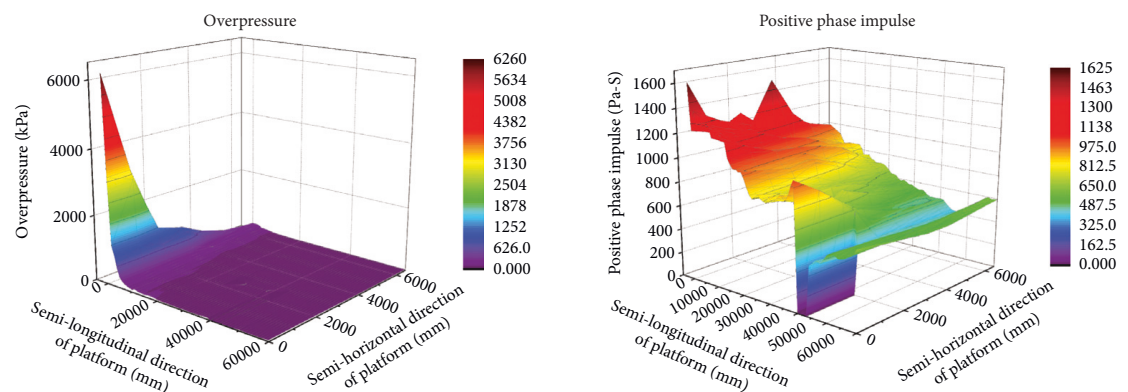

(c)
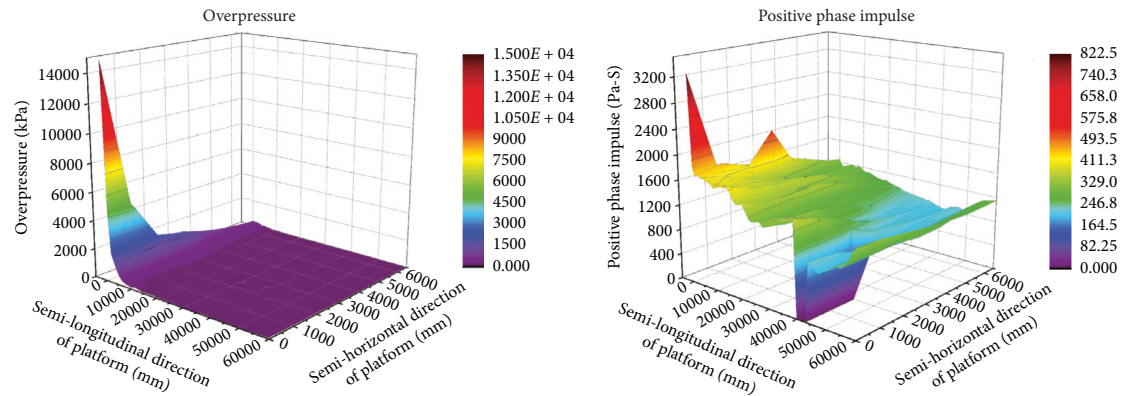

(d)
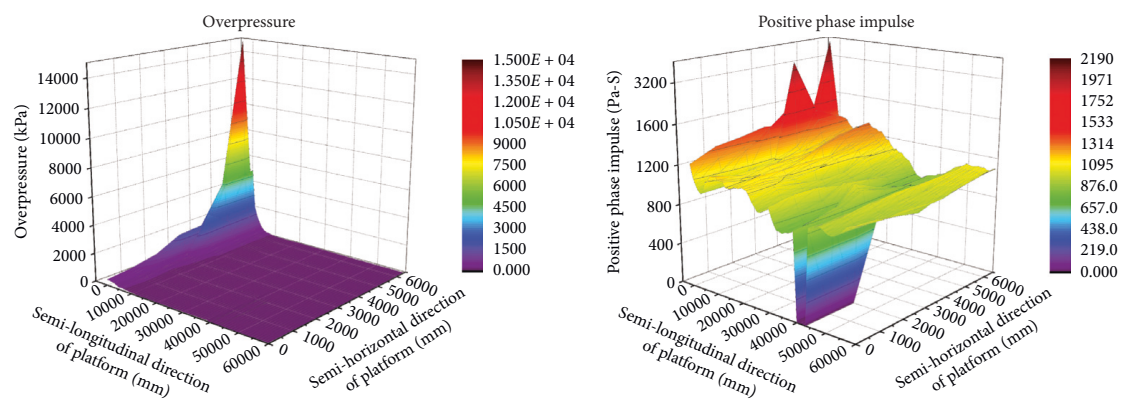

(e)
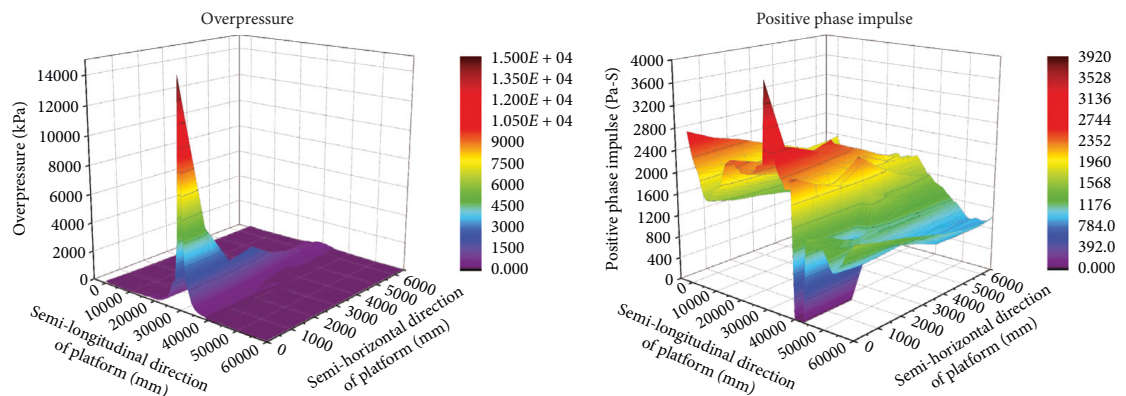

(f)
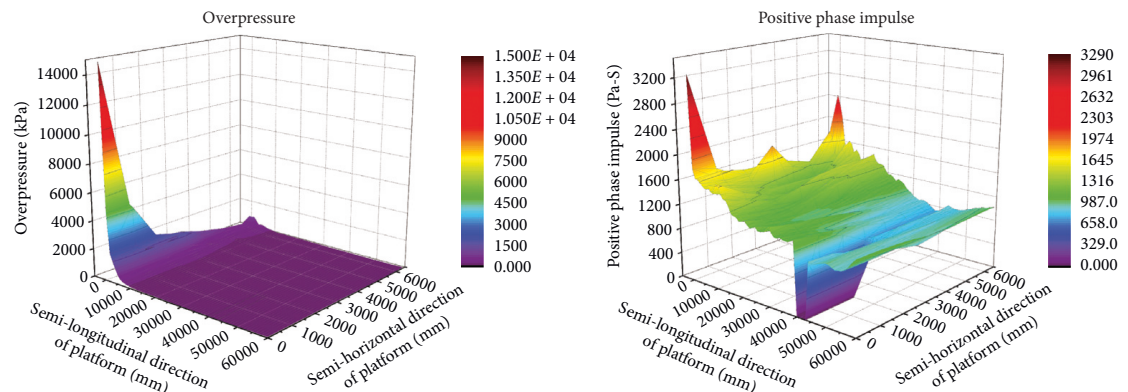

(g)

FIgUre 10: Continued. 

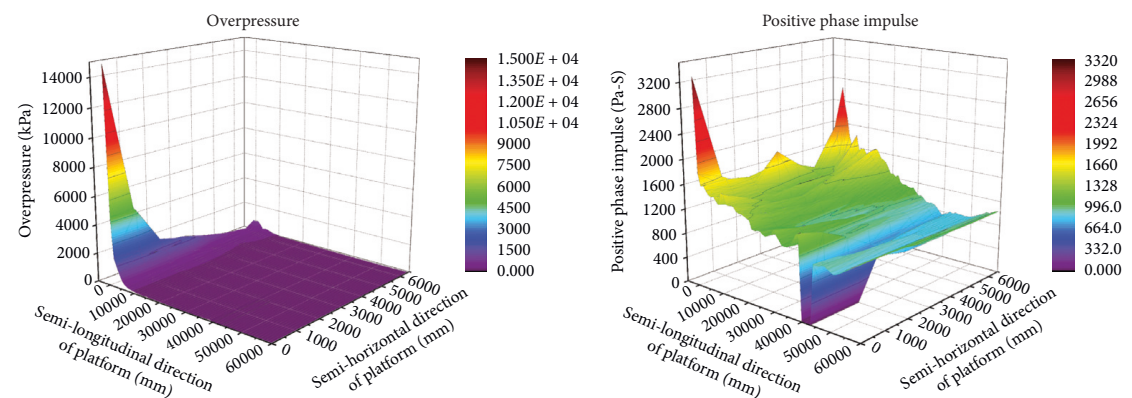

(h)
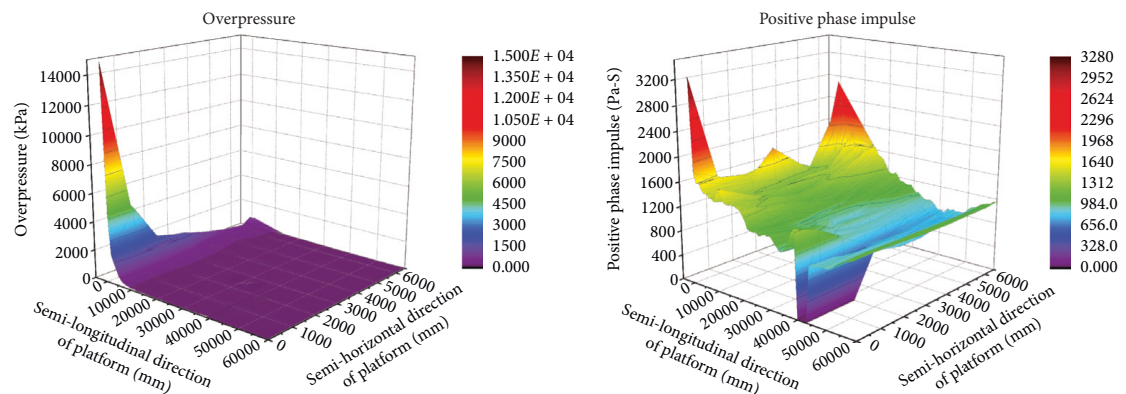

(i)

FIGURE 10: Spatial distribution of shock wave overpressure and positive phase impulse under different conditions.

TABLE 3: Comparative analysis of the strength of shock waves for the explosion on the platform.

\begin{tabular}{|c|c|c|c|c|c|c|c|c|}
\hline \multirow[t]{2}{*}{ No. } & \multirow{2}{*}{\multicolumn{2}{|c|}{ Location }} & \multirow[t]{2}{*}{ Structure } & \multirow[t]{2}{*}{ Explosive charge (kg) } & \multicolumn{2}{|c|}{$\begin{array}{c}\text { Overpressure } \\
(\mathrm{kPa})\end{array}$} & \multicolumn{2}{|c|}{ Impulse $(\mathrm{Pa} \cdot \mathrm{s})$} \\
\hline & & & & & $\max$ & $\min$ & $\max$ & $\min$ \\
\hline 1 & \multirow{4}{*}{\multicolumn{2}{|c|}{ Center of the platform }} & \multirow{4}{*}{ No shield door } & 5 & 1610.668 & 5.668 & 760.325 & 106.337 \\
\hline 2 & & & & 10 & 2568.668 & 8.668 & 1040.437 & 191.114 \\
\hline 3 & & & & 20 & 3260.668 & 13.668 & 1550.359 & 363.412 \\
\hline 4 & & & & 40 & 14998.668 & 19.668 & 3283.549 & 741.108 \\
\hline 5 & Edge of the platform & & No shield door & 40 & 14998.668 & 21.668 & 2182.809 & 738.794 \\
\hline 6 & Entrance to the stairs & & No shield door & 40 & 14998.668 & 24.668 & 3919.905 & 853.642 \\
\hline 7 & \multirow{3}{*}{ Center of the platform } & \multirow{3}{*}{ Shield door } & Half-height & 40 & 14998.668 & 20.668 & 3287.955 & 636.178 \\
\hline 8 & & & Full-height and semiclosed & 40 & 14998.668 & 18.668 & 3318.273 & 679.359 \\
\hline 9 & & & Full-height and fully closed & 40 & 14998.668 & 17.668 & 3277.545 & 668.942 \\
\hline
\end{tabular}

certain extent behind the stair. That is because the stair and the column play a certain blocking effect on the shock wave. Moreover, when there is a shield door structure on the platform, the safety area on the platform is larger than other cases. The higher the shield door structure is, the larger the safety area behind the stair is. At the early stage of the explosion, the shock wave with large energy is blown through the shield door into the track area, resulting in a pressure relief effect. With the increase of the shock wave propagation distance, shield door on the platform plays a certain interception effect on the shock wave from the track area, which weakens the energy of the shock wave on the platform.

Due to the pressure relief effect of the stair, the shock wave overpressure and impulse are greatly increased, thereby increasing the degree of injury of the person at the position. When the explosive charge at the center of the platform is $5 \mathrm{~kg}$ and $10 \mathrm{~kg}$, respectively, a separate light injury area appears at the slope of the stair, and other locations in the same section are safe. Similarly, when the explosives explode at the entrance to stair, the casualty at the slope of the stairs is also significantly higher than other areas of the same section.

Due to the reflection and diffraction of the shock wave caused by the platform column, the casualty of the explosionfacing surface of the column is greater than that of other locations in the same explosion distance and the casualty of the back-explosion surface of the column is relatively small compared with the surrounding. When the shock wave propagates to the end wall of the platform, the shock wave overpressure and impulse near the end wall increase due to the reflection of the end wall of the platform. So, when the explosives of $10 \mathrm{~kg}$ and $20 \mathrm{~kg}$ explode at center of the platform, there is a separate light injury area near the end wall.

The death and injury distance of personnel on the platform under different conditions (centered on the explosion source) is shown in Table 4. 

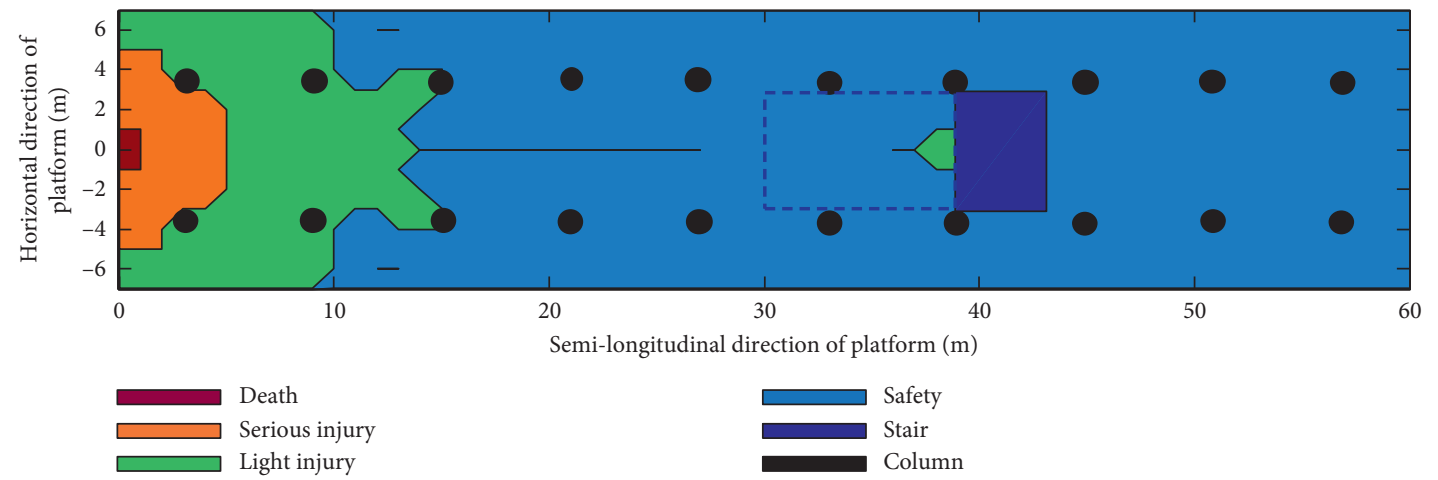

(a)
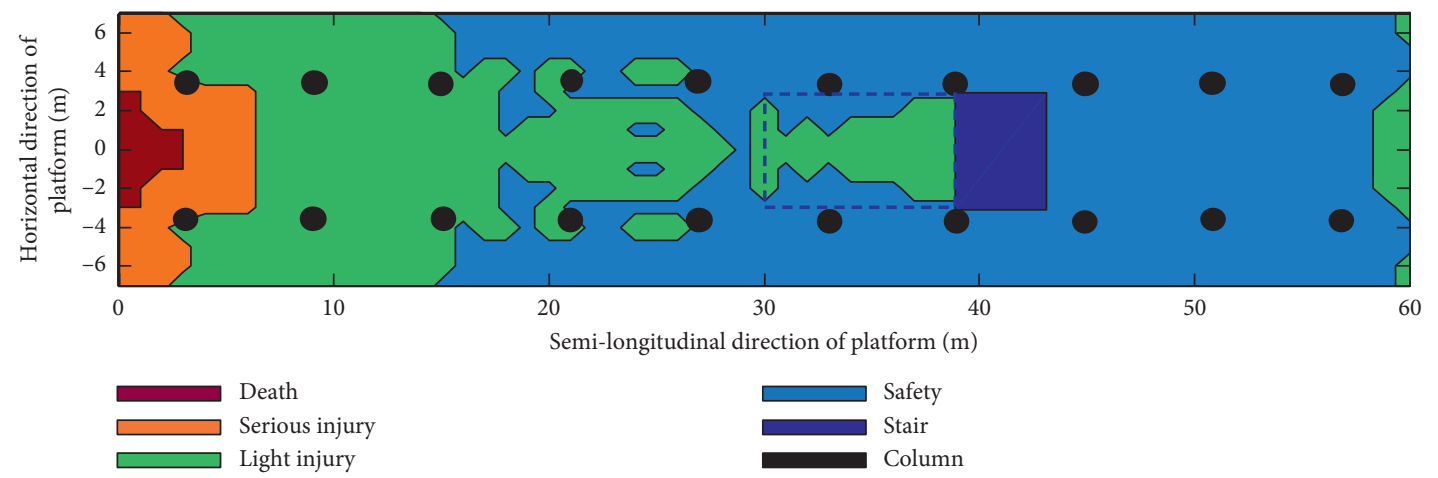

(b)
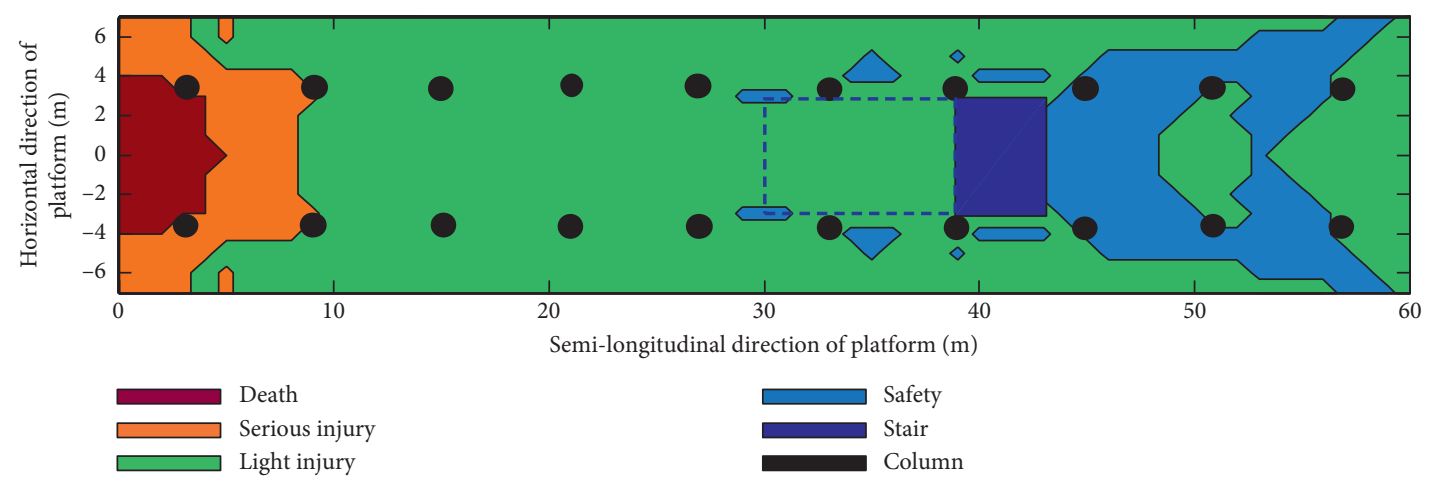

(c)
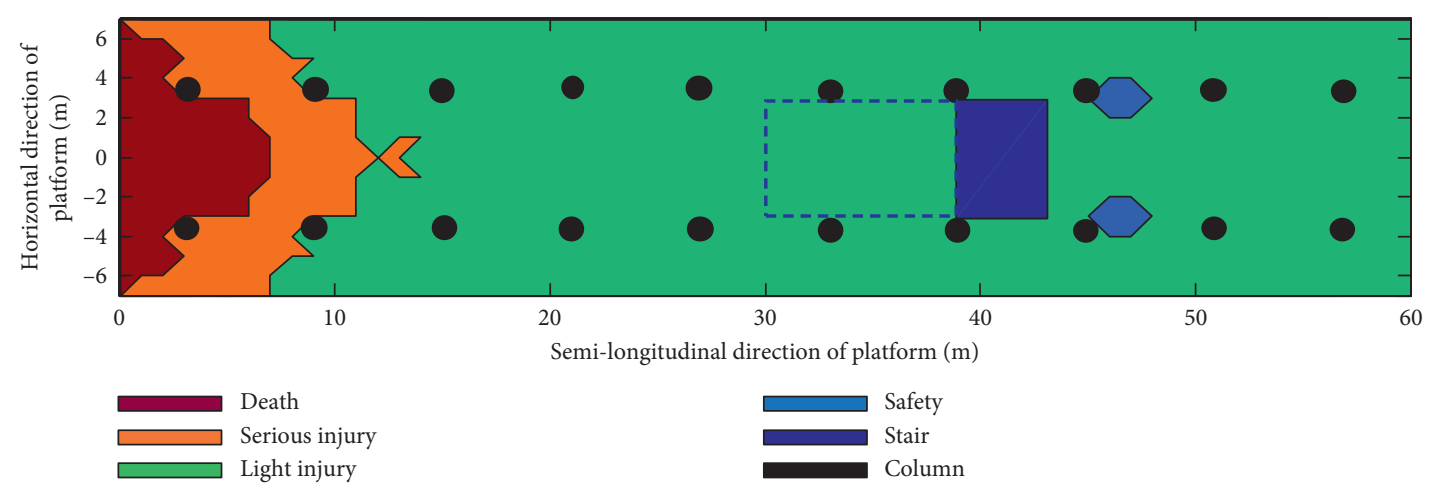

(d)

Figure 11: Continued. 

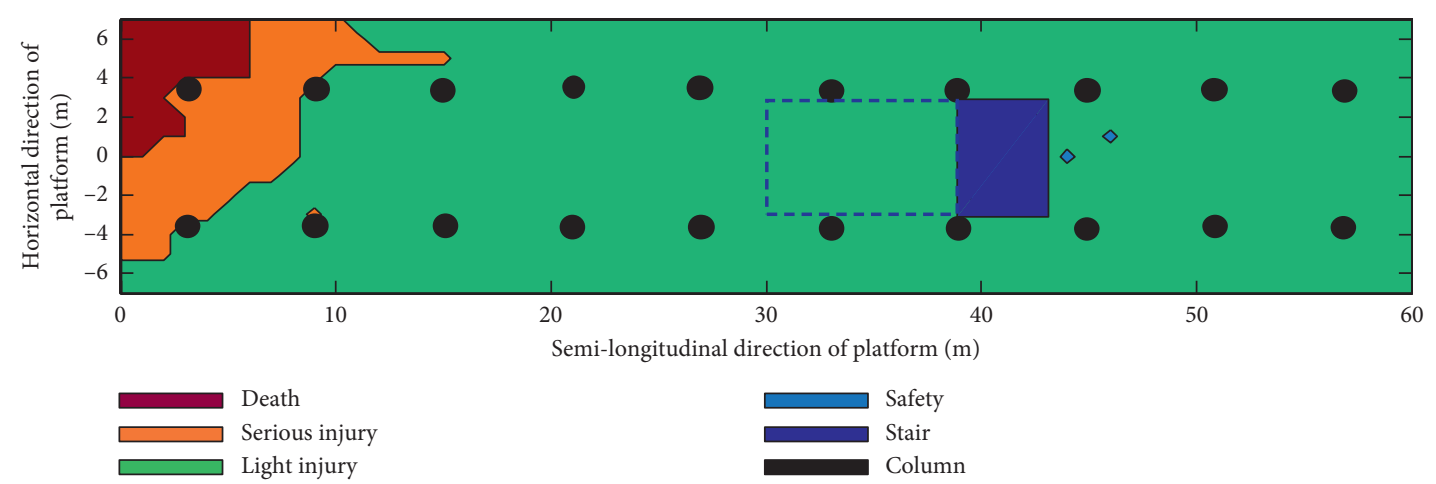

(e)
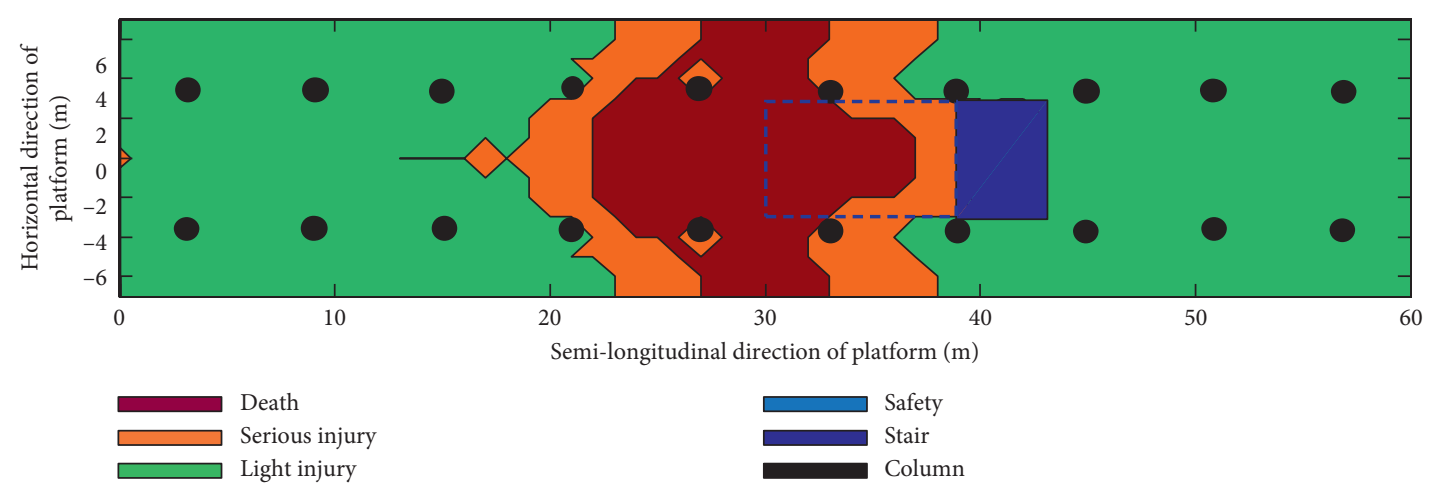

(f)
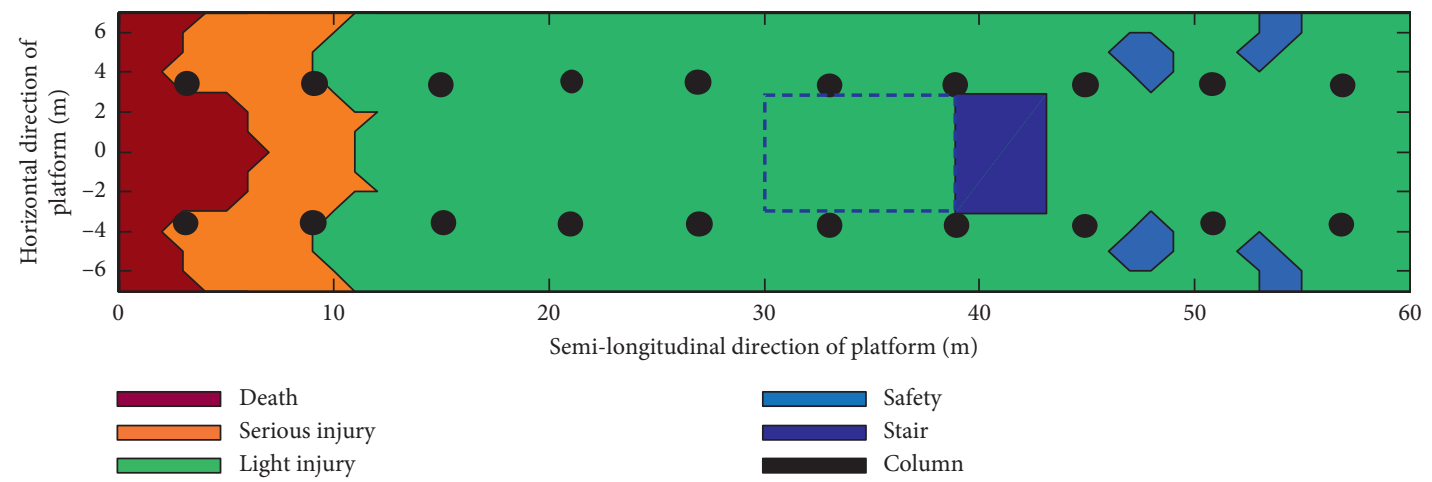

(g)

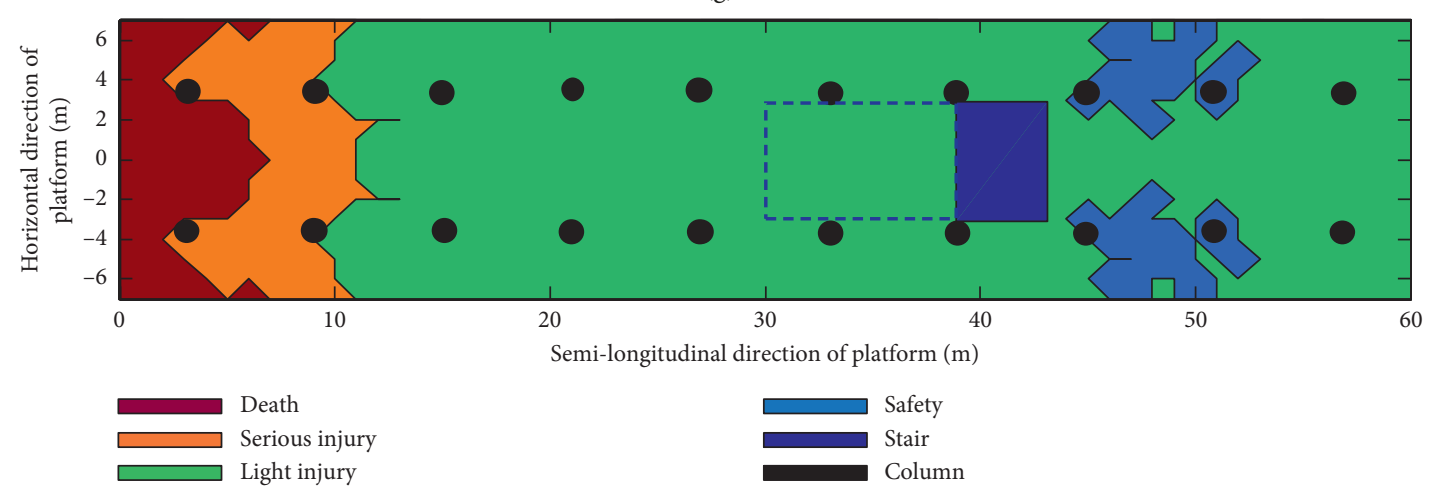

(h)

Figure 11: Continued. 


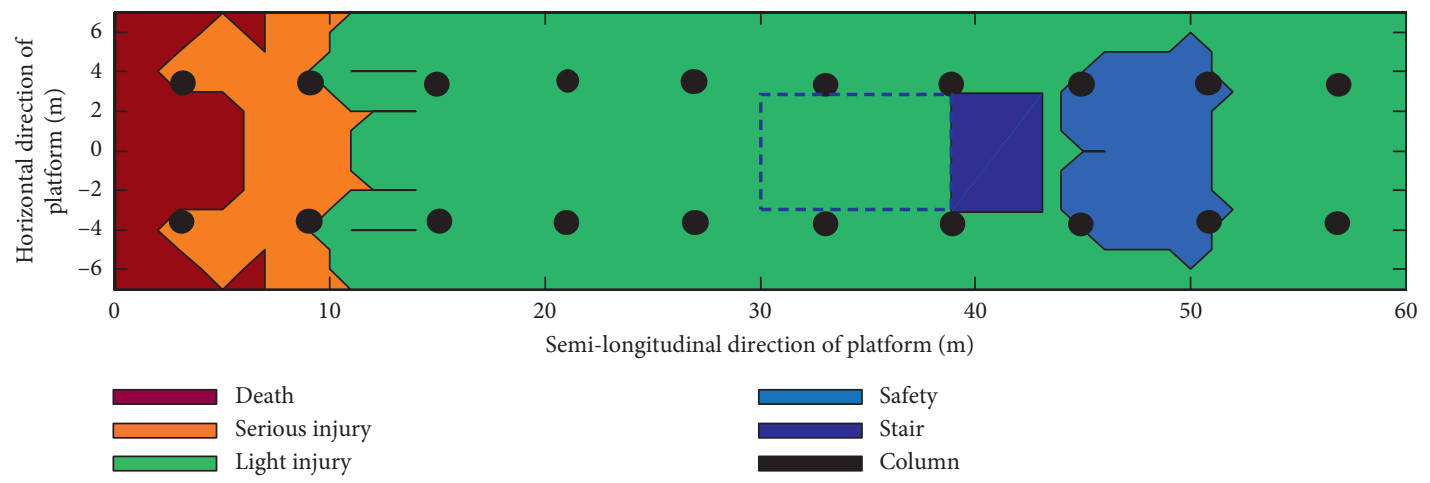

(i)

FIgure 11: Distribution map of casualties. (a) $5 \mathrm{~kg}$ TNT exploding at the center of the platform. (b) $10 \mathrm{~kg}$ TNT exploding at the center of the platform. (c) $20 \mathrm{~kg}$ TNT exploding at the center of the platform. (d) $40 \mathrm{~kg}$ TNT exploding at the center of the platform. (e) $40 \mathrm{~kg}$ TNT exploding at the edge of the platform. (f) $40 \mathrm{~kg}$ TNT exploding at the entrance to the stair. (g) $40 \mathrm{~kg}$ TNT exploding on the platform with halfheight shield door. (h) $40 \mathrm{~kg}$ TNT exploding on the platform with full-height and semiclosed shield door. (i) $40 \mathrm{~kg}$ TNT exploding on the platform with full-height and fully closed shield door.

TABLE 4: Casualty distance of personnel for explosion in subway platform.

\begin{tabular}{|c|c|c|c|c|c|c|}
\hline \multicolumn{2}{|c|}{ Subway structure } & $\begin{array}{c}\text { Location of explosion } \\
\text { source }\end{array}$ & $\begin{array}{c}\text { TNT } \\
\text { equivalent } \\
(\mathrm{kg})\end{array}$ & $\begin{array}{c}\text { Death } \\
\text { distance } \\
(\mathrm{m})\end{array}$ & $\begin{array}{l}\text { Distance of serious } \\
\text { injury }(\mathrm{m})\end{array}$ & $\begin{array}{l}\text { Distance of light } \\
\text { injury }(\mathrm{m})\end{array}$ \\
\hline \multirow{6}{*}{\multicolumn{2}{|c|}{ No shield door }} & \multirow{4}{*}{ Center of the platform } & 5 & 1.414 & 5.385 & 39.000 \\
\hline & & & 10 & 4.243 & 6.800 & 60.351 \\
\hline & & & 20 & 5.000 & 11.000 & 60.351 \\
\hline & & & 40 & 6.083 & 12.000 & 60.351 \\
\hline & & Edge of the platform & 40 & 6.575 & 15.074 & 61.392 \\
\hline & & Entrance to the stairs & 40 & 8.246 & 17.000 & 30.696 \\
\hline \multirow{3}{*}{ Shield door } & Half-height & \multirow{3}{*}{ Center of the platform } & \multirow{3}{*}{40} & 8.845 & 12.776 & 60.351 \\
\hline & Full-height and semiclosed & & & 9.552 & 13.152 & 60.351 \\
\hline & Full-height and fully closed & & & 9.552 & 14.560 & 60.351 \\
\hline
\end{tabular}

According to Table 4, combined with dimensional analysis [20], the quantitative relationship between the explosive charge and the casualty distance for the condition of explosion at center of the platform with no shield door can be fitted, that is,

$$
R=a \sqrt[3]{w}
$$

where $R$ is the casualty distance, $\mathrm{m}$; $a$ is a constant; and $w$ is the TNT equivalent, $\mathrm{kg}$.

For the death distance, $a$ is 1.8357 , and the fitting correlation coefficient is 0.99798 . For the distance of serious injury, $a$ is 3.3693 , and the fitting correlation coefficient is 0.99647.

\section{Conclusion}

According to the characteristics of shock wave propagation in the closed structure, ASII-based comprehensive casualty assessment method and process are established. Based on the investigation of the structure size of the subway platform and the cases of the explosion terrorist attack in the subway, the numerical models of the explosion in the subway platform under different conditions are established. The spatial distribution law of the overpressure and positive phase impulse of the shock wave in the platform is obtained. The ASIIbased comprehensive assessment method for casualties is used to obtain the distribution map of casualties under different conditions. It deserves further study on how to develop an efficient and accurate calculation method to simulate the propagation of the explosion shock wave in the large-scale structure of the subway.

\section{Data Availability}

All data included in this study are available from the corresponding author upon request.

\section{Conflicts of Interest}

The authors declare that there are no conflicts of interest regarding the publication of this paper.

\section{Acknowledgments}

This work was supported by the National Key Research and Development Program of China (no. 2017YFC0803308-05) and National Social Science Foundation of China (grant no. 15BFX059). Special thanks are given to Ph.D Nafeng Wang for her helpful consultation in accomplishing this paper. 


\section{References}

[1] F. Rigas and S. Sklavounos, "Experimentally validated 3-D simulation of shock waves generated by dense explosives in confined complex geometries," Journal of Hazardous Materials, vol. 121, no. 1-3, pp. 23-30, 2005.

[2] M. Larcher, F. Casadei, and G. Solomos, "Risk analysis of explosions in trains by fluid-structure calculations," Journal of Transportation Security, vol. 3, no. 1, pp. 57-71, 2010.

[3] C. Wu, Y. Lu, H. Hao, W. K. Lim, Y. Zhou, and C. C. Seah, "Characterisation of underground blast-induced ground motions from large-scale field tests," Shock Waves, vol. 13, no. 3, pp. 237-252, 2003.

[4] Z. X. Li, Y. Liu, and L. Tian, "Dynamic response and antiexplosion analysis of two-line subway tunnel under blast loading in a unilateral tunnel," Journal of Beijing University of Technology, vol. 32, no. 2, pp. 173-181, 2006.

[5] S. Choi, J. Wang, G. Munfakh, and E. Dwyre, "3D nonlinear blast model analysis for underground structures," in Proceedings of the Geotechnical Engineering in the Information Technology Age, Atlanta, GA, USA, February 2006.

[6] US Department of Defense, Structure to Resist the Effects of Accidental Explosions TM5-1300, Departments of the Army, Navy, and Air Force, Washington, DC, USA, 1990.

[7] Z. Li, "Safe distance of human under the action of air shock wave," Explosion and Shock Waves, vol. 10, no. 2, pp. 135-144, 1990.

[8] Z. Y. Li, Y. Long, and X. S. Tang, "Experimental study on the killing distance of explosive impact loads on animals," Journal of Safety and Environment, vol. 5, no. 1, pp. 84-86, 2005.

[9] C. M. Pietersen, "Consequences of accidental releases of hazardous material," in Proceedings of the First International Conference on Loss of Containment, London, UK, September 1989.

[10] E. G. Ferradás, F. D. Alonso, J. F. S. Pérez, A. M. Aznar, J. R. Gimeno, and M. D. Miñarro, "Consequence analysis by means of characteristic curves to determine the damage to humans from bursting spherical vessels," Process Safety and Environmental Protection, vol. 86, no. 2, pp. 121-129, 2008.

[11] M. A. Mayorga, "The pathology of primary blast overpressure injury," Toxicology, vol. 121, no. 1, pp. 17-28, 1997.

[12] F. P. Lees, Loss Prevention in the Process Industries, Hazard Identification, Assessment and Control, Butterworth-Heinemann, London, UK, 2001.

[13] I. G. Bowen, E. R. Fletcher, and D. R. Richmond, Estimate of Man's Tolerance to the Direct Effects of Air Blast. DASA 2113, Lovelace Foundation for Medical Education and Research, Albuquerque, NM, USA, 1968.

[14] H. Axelsson and J. T. Yelverton, "Chest wall velocity as a predictor of nonauditory blast injury in a complex wave environment," Journal of Trauma: Injury Infection and Critical Care, vol. 40, no. 3, pp. 31S-36S, 1996.

[15] J. Doormaal and M. Horst, "An approximation procedure of the Axelsson model for quick injury prediction," in Proceedings of the 21st International Symposium of Military Aspects of Blast and Shock, Jerusalem, Israel, October 2010.

[16] I. Häring, Risk Analysis and Management: Engineering and Resilience, Chapter 3, Springer, Singapore, 2015.

[17] D. J. Finney, Probit Analysis: A Statistical Treatment of the Sigmoid Response Curve, Chapter 1, Cambridge: at the University Press, Cambridge, UK, 1952.

[18] D. M. Yu, C. G. Feng, Q. X. Zeng, and X. Y. Guo, "Destruction of explosion and damage partition," Chinese Journal of Safety Science, vol. 5, pp. 13-17, 1995.
[19] The Federal Emergency Management Agency, FEMA 452 A How-to Guide to Mitigate Potential Terrorist Attacks Against Buildings, The Federal Emergency Management Agency, Washington, DC, USA, 2005.

[20] Z. P. Wang and Z. L. Zheng, Explosion and Its Protection, Chapter 3, The Publishing House of Ordnance Industry, Beijing, China, 2008. 


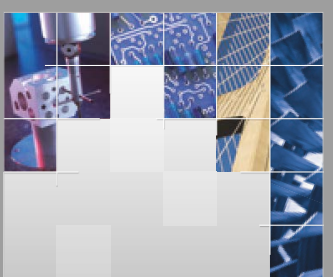

\section{Enfincering}
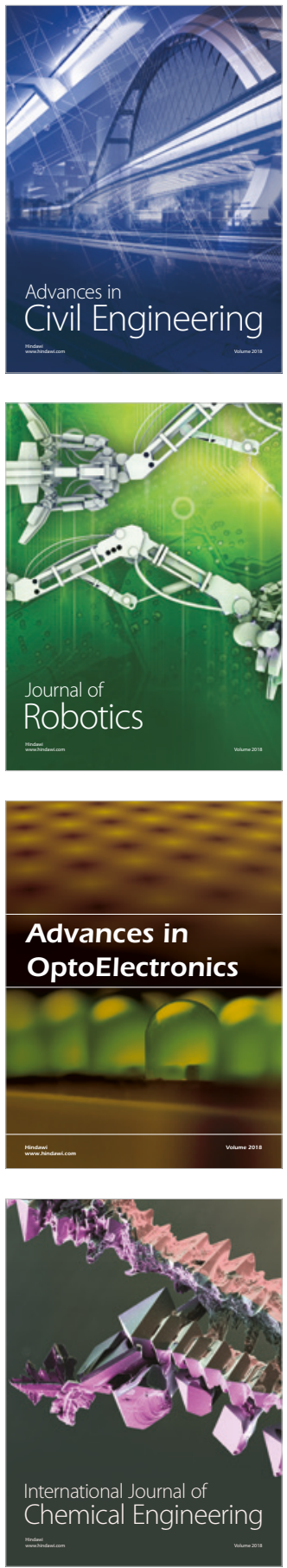

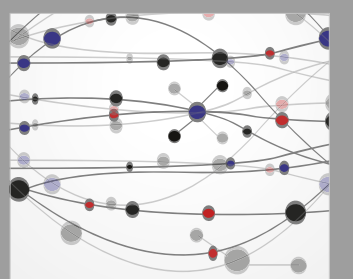

\section{Rotating \\ Machinery}

The Scientific World Journal

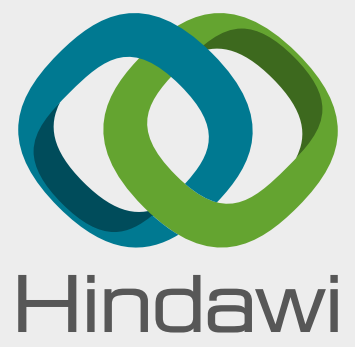

Submit your manuscripts at

www.hindawi.com
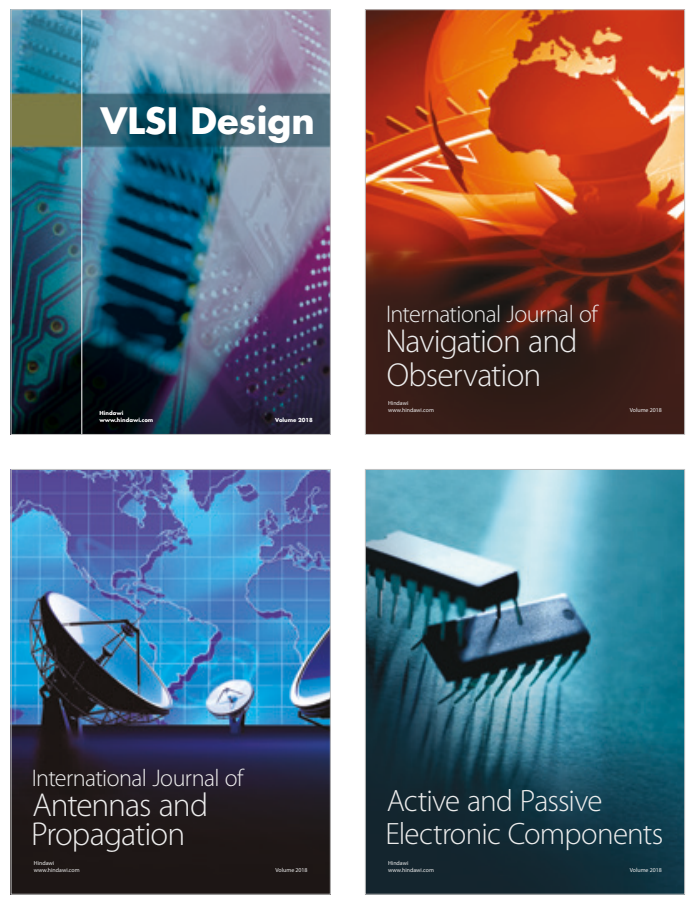
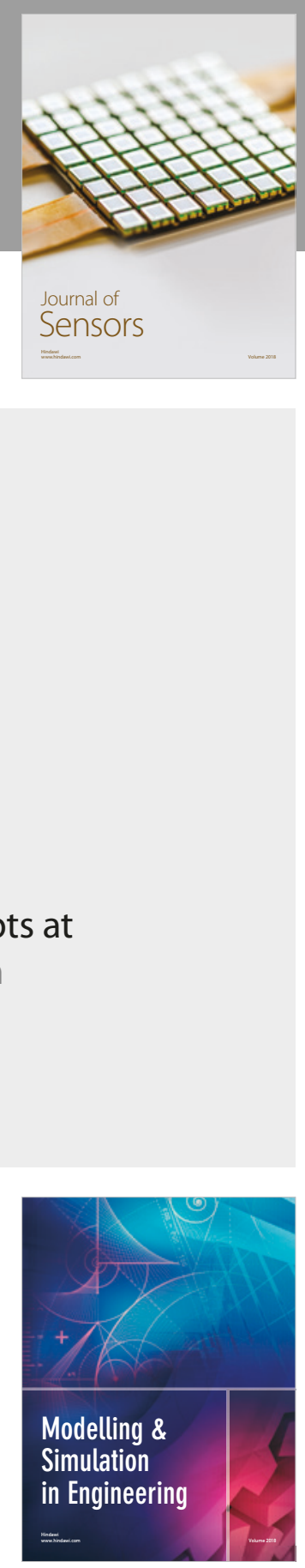

\section{Advances \\ Multimedia}
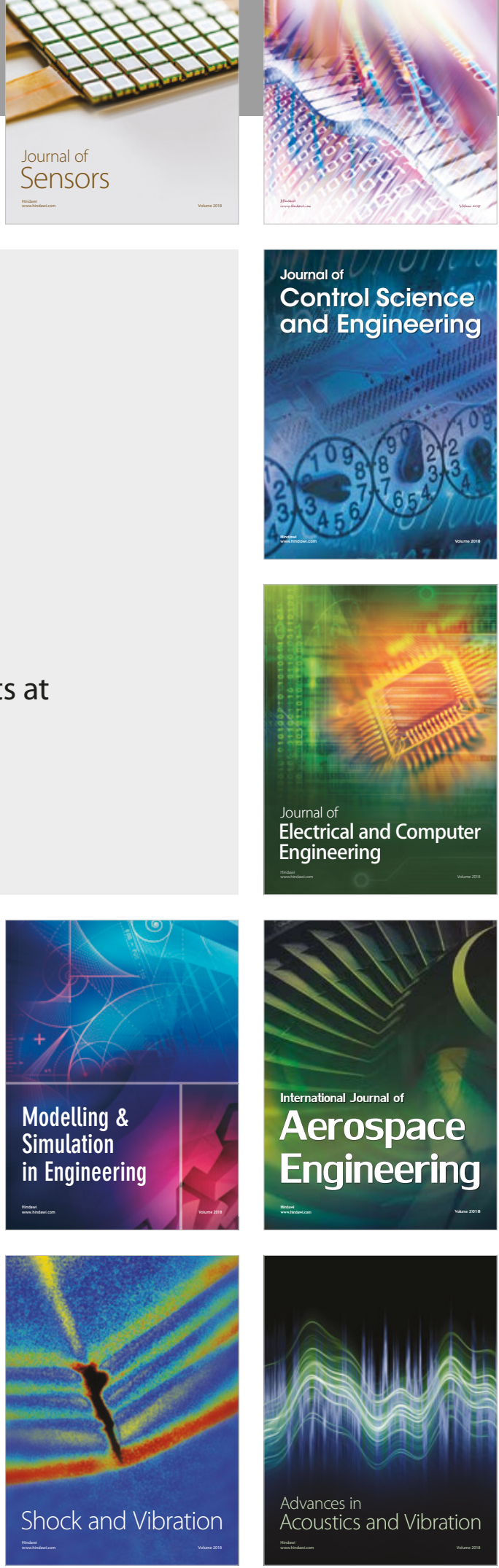